\title{
Literature Review on Network Design Problems in Closed Loop and Reverse Supply Chains
}

\author{
Muthusamy Aravendan', Ramasamy Panneerselvam² \\ ${ }^{1}$ Department of Leather Design (Footwear \& Products), National Institute of Fashion Technology, \\ Chennai, India \\ ${ }^{2}$ Department of Management Studies, School of Management, Pondicherry University, Pondicherry, India \\ Email: $\underline{m}$ aravendan@rediffmail.com, panneerdms@yahoo.co.in
}

Received 6 March 2014; revised 5 April 2014; accepted 1 May 2014

Copyright (C) 2014 by authors and Scientific Research Publishing Inc.

This work is licensed under the Creative Commons Attribution International License (CC BY).

http://creativecommons.org/licenses/by/4.0/

(c) (i) Open Access

\begin{abstract}
The productivity of an organization is very much affected by non-value adding activity like logistics, which moves the resources from suppliers to factory, raw materials/semi-finished items within the factory and finished goods from factory to customers via a designated distribution channel called as forward logistics. In some cases, parts of the products such as automobiles, computers, cameras, mobile phones, washing machines, refrigerators, garments, footwear and empty glass bottles of beverages, etc. will be brought back to the factories as a product recovery strategy through reverse logistics network which is integrated in a sustainable closed loop supply chain network. So, it is highly essential to optimize the movement of the items in the reverse logistics network. This paper gives a comprehensive review of literature of the design of networks for the reverse logistics as well as for the reverse logistics coupled with forward logistics. The contributions of the researchers are classified into nine categories based on the methods used to design the logistics network.
\end{abstract}

\section{Keywords}

Supply Chain, Network Design, Closed-Loop, Reverse Logistics, Models, Heuristics, Algorithms

\section{Introduction}

Supply Chain Management is an integrating function with primary responsibility for linking major business functions and business processes within and across companies into a cohesive and high-performing business

How to cite this paper: Aravendan, M. and Panneerselvam, R. (2014) Literature Review on Network Design Problems in Closed Loop and Reverse Supply Chains. Intelligent Information Management, 6, 104-117. 
model. It includes all of the Logistics Management activities as well as manufacturing operations, and it drives coordination of processes and activities within and across marketing, sales, product design, finance, and information technology. Logistics management is that part of the supply chain management process, which plans, implements, and controls the efficient, effective forward and reverse flows and storage of goods, services, and related information between the point of origin and the point of consumption in order to meet customers' requirements.

\subsection{Drivers and Metrics of Supply Chain}

The drivers of supply chain performance are classified into logistical drivers, viz. facilities, inventory and transportation and cross functional drivers, viz. information, sourcing and pricing. The improvement in the supply chain performance of a company in terms of responsiveness and efficiency is analyzed and assessed by examining these logistical and cross functional drivers. Metrics are the measures of various factors related to the drivers which influence the performance of the supply chain. The logistics drivers are facilities, inventory and transportation. Facilities are the actual physical locations in the supply chain network where product is stored, assembled, or fabricated. The two major types of facilities are production sites and storage sites. The facility related metrics that influence the supply chain performance are capacity, utilization, theoretical flow/cycle time of production, actual average flow/cycle time, flow time efficiency, product variety, volume contribution of top 20 percent SKUs and customers, processing/setup/down/idle time, average production batch size and production service level.

Inventory is held throughout the supply chain in the form of raw materials, work in progress and finished goods. The inventory related metrics that influence the supply chain are average inventory, products with more than a specified number of days of inventory, average replenishment batch size, average safety inventory, seasonal inventory, fill rate and fraction of time out of stock. Transportation moves product between different stages in a supply chain. The mode of transportation can be chosen between air, truck, rail, sea and pipeline. The transportation related metrics that influence the supply chain are: average inbound transportation cost, average incoming shipment size, average inbound transportation cost per shipment, average outbound transportation cost, average outbound shipment size, average outbound transportation cost per shipment and fraction supported by mode.

The cross functional drivers are information, sourcing, and pricing. Information serves as the connection between various stages of a supply chain, allowing them to coordinate and maximize total supply chain profitability. The information related metrics that influence the supply chain are forecast horizon, frequency of update, forecast error, seasonal factors, variance from plan and ratio of demand. Sourcing is the set of business processes required to purchase goods and services. The sourcing related metrics that influence the supply chain are: days payable outstanding, average purchase price, range of purchase price, average purchase quantity, fraction on-time deliveries, supply quality and supply lead time. Pricing is the process through which a firm decides how much to charge customers for its goods and services. The pricing related metrics that influence the supply chain are profit margin measures, day sales outstanding, incremental fixed cost per order, incremental variable cost per unit, average sale price, average order price, range of sale price and range of periodic sales.

\subsection{Classifications of SCM}

The classifications of SCM are lean supply chain, agile supply chain, closed loop supply chain, reverse supply chain (reverse logistics) and green supply chain. Lean supply chain is a properly designed process in which all the supply chain functions and activities are systematically executed. Supply Chain Agility is an operational strategy focused on inducing velocity and flexibility in the supply chain. Closed-loop supply chain (CLSC) integrates both forward and reverse supply chains and focuses on taking back products from customers and recovering added value by reusing the entire product, and/or some of its modules, components, and parts. Reverse logistics stands for all operations related to the reuse of products and materials. It is the process of planning, implementing, and controlling the efficient, cost effective flow of raw materials, in-process inventory, finished goods and related information from the point of consumption to the point of origin for the purpose of recapturing value or proper disposal. The reverse logistics process includes the management and the sale of surplus as well as returned equipment and machines from the hardware leasing business. Normally, logistics deals with events that bring the product towards the customer. In the case of reverse, the resource goes at least one step 
back in the supply chain. For instance, goods move from the customer to the distributor or to the manufacturer. Green supply chain is defined as 'integrating environmental thinking into supply chain management, including product design, material sourcing and selection, manufacturing processes, delivery of the final product to the consumers as well as end-of-life management of the product after its useful life.

\section{Network Design in Supply Chain}

Network design decisions are among the most important supply chain decisions, as their implications are significant and long lasting. In designing a supply chain, we need to consider how all supply chain drivers-facilities, transportation, inventory, information, sourcing and pricing should be used together to support the competitive strategy of a firm and maximize supply chain profits. Distribution occurs between every pair of stages in the supply chain. Raw materials and components are moved from suppliers to manufacturers, whereas finished products are moved from the manufacturer to the end consumer. Distribution is a key driver of the overall profitability of a firm because it affects both the supply chain cost and the customer experience directly.

The distribution network from the manufacturer to the end consumer has many choices. Based on the two key decisions i.e. whether the product will be delivered to the customer location or picked up from a preordained site and whether the product will flow through an intermediary (or intermediate location), the firm can use one of the six distinct distribution network designs to move the products from factory to consumer, which are as listed below:

- Manufacturer storage with direct shipping;

- Manufacturer storage with direct shipping and in-transit merge;

- Distributor storage with package carrier delivery;

- Distributor storage with last-mile delivery;

- Manufacturer/Distributor storage with customer pick up;

- Retail storage with customer pick up.

\section{Literature Review}

In the growing global competition, logistics plays vital role, which identifies the facility locations, installations, operations and maintenance and day-to-day transportations from plant to customers and back in the process of satisfying customer demands and bringing back the returns if any for different purposes as stated in reverse logistics. The logistics is broadly classified into forward logistics and reverse logistics. There are many studies for forward logistics. In this paper, the closed loop supply chain which encompasses forward and reverse logistics, and reverse logistics are considered.

The design of network for supply chain facilitates organizations to improve productivity in terms of reduced logistics cost, operation cost and maintenance cost.

In this section, the review of the design of reverse logistics network as well as the reverse logistics network in conjunction with forward logistics network is presented under the following nine categories, viz. models, branch and bound algorithms, heuristics, genetic algorithms, simulated annealing algorithms, Petri net algorithms, analytic hierarchy process (AHP), simulation approaches and general approaches.

\subsection{Models}

The mathematical models for the closed loop supply chain as well as reverse logistics aim to provide optimal solution in terms of network design. This section provides review of literature of mathematical models applied to the design of supply chain networks, both closed and reverse logistics system.

Krikke et al. [1] developed a quantitative model for concurrent product design considering the modularity, reparability and recyclability, and closed loop supply chain design with an application to refrigerators. They experimented the model for different scenarios using different parameters settings like centralized versus decentralized processing, alternative product designs, varying quality and quantity, and potential environmental legislation based on producer responsibility. Schultmann et al. [2] presented modeling of reverse logistics tasks within closed loop supply chains based on an example considering the end of life vehicle (ELV) treatment practiced in the automobile industry of Germany. They proposed different design options for a closed loop supply chain concentrating on the handling the reverse material flows to reintegrate them into their genuine supply chains. 
They modeled the reverse logistics aspects with vehicle routing planning and developed a problem-tailored algorithm. Salema et al. [3] proposed a warehouse-based design model for reverse logistics network which simultaneously optimizes the forward and reverse networks. They designated the model as DeM, a coordinated warehouse location model, which integrates forward and reverse flows. Savaskan et al. [4] presented a reverse channel design with the case of competing retailers to collect post-consumer goods in reverse channel and to take strategic product pricing decisions in the forwards channel. They introduced product remanufacturing into the single manufacturer-two retailer, multi-echelon distribution model and presented two decentralized and two coordinated closed loop supply chain models. The model suggests the retailer collecting system as a preferred option for the manufacturer of consumer products in which completion is an important determinant of prices. The model also suggests that the retailer collecting system is the better channel structure for the Kodak's single use camera product line in which the ability to compete in prices with other manufacturers' products is critical. Salema et al. [5] proposed an optimization model for the design of a capacitated multi-product reverse network with uncertainty. The model is a generalized one aimed to overcome the limitations in the existing models as most of them are case based and lack generality in application. They considered capacity limits, multi-product management and uncertainty on product demands in order to contemplate the generic network design for reverse logistics. The model is solved by developing a mixed integer formulation and solved using B\&B techniques. Ondemir and Gupta [6] presented a mixed integer non-linear programming model to select collection centers for reverse logistic networks. The model was applied to find the optimal locations of a predetermined number of collection centers, the optimal vehicle type and the optimal incentive to be offered by the company to product holders based on the quality condition of their used items. They developed a tabu search based algorithm in MATLAB to solve this NP-complete problem. They found that the location dependent transportation cost approach is inferior to fixed transportation cost approach resulting in higher loss of profit when the variation of the cost with respect to location is relatively high.

Mansour and Zarei [7] proposed a multi-period reverse logistics optimization model for end-of-life vehicles recovery based on EU Directive which imposes new additional costs on manufacturers. The model was developed based on the number, location and the capacity of the collection centers, dismantlers and the amount of materials flow between different facilities. They found the solution by applying multiple start search algorithm where a heuristic method was performed in each iteration. Demirel and Gokcen [8] developed a mixed integer programming model for remanufacturing in reverse logistics environment which includes multi-phase and multi-product forward and reverse distribution. They presented three different scenarios with a low, medium and high rate of returns in order to compare the possible performance of different scenarios for allowing the logistics planner to take a better decision. Lashkari and Zhang [9] presented a modeling and analysis of a reverse supply chain network for lead acid battery manufacturing industry. They encompassed the entire closed loop process which includes purchasing, production, end of life product collection and recycling. The model presented is a multi-objective, multi echelon mixed integer linear program which minimizes the total cost of the operations and the total pollution emissions in the closed loop network. Barker and Zabinsky [10] presented a framework for deciding reverse logistics network design. They mainly focused on two decision making phases, viz. the strategic phase for facility location decisions and tactical phase for customer flow allocation decisions. They also considered the critical trade-offs from which they identified relevant network design decisions for each flow stage, viz. collection, sorting/testing and processing to make efficient network design. Reynaldo and Ertel [11] presented a reverse logistics network design in a closed loop supply chain for the end-of-life vehicles in Mexico. They handled the problem through reverse logistics and modeled it through an un-capacitated facility location problem. Kannan et al. [12] developed a multi-criteria group decision making model in fuzzy environment to guide the selection process of the best 3PRLP. They analyzed the selection of best 3PRLP from among 15 options through interpretive structural modeling(ISM) and fuzzy technique for order preference by similarity to ideal solution (TOPSIS). A case study on battery manufacturing industry in India is presented to illustrate the effectiveness of the model which showed that the proposed ISM based model can provide the decision maker with a more realistic representation of the problem while considering interactions among the criteria for the selection of best 3PRLP in the company. Mutha and Pokharel [13] presented a model for strategic network design of reverse logistics and remanufacturing using new and old product modules. They assumed that the returned products are consolidated in the warehouse before they are sent to reprocessing centers for inspection and dismantling. Dismantled parts are sent for remanufacturing or to the secondary market as spare parts. On simulating the model with different quantities of returned products, it is concluded that it might be beneficial to locate 
processing centers at location where resources, viz. labour, energy and land are cheaper and to locate remanufacturing centers at places where new modules of the remanufactured products are available at cheaper rate. El-Sayed et al. [14] developed a multi-period, multi-echelon forward-reverse logistics network design under risk. The network structure includes three echelons in the forward direction (suppliers, facilities and distribution centers) and two echelons in the reverse direction (disassembly and redistribution centers), first customer zones in which the demands are stochastic and second customer zones in which the demand is assumed to be deterministic, but it may also assumed to be stochastic. They formulated a stochastic mixed integer linear programming (SMILP) for this problem. Dahel [15] considered the design of a multi-echelon, closed loop supply chain network and the planning of product recovery for remanufacturing under uncertainty. In the network, they included a number of plants and disassembly centers of unknown location and a number of customer zones and disposal sites at fixed locations. They modeled it as a multi-period cost minimizing stochastic programming problem to determine the location of plants and disassembly centers and to specify the optimal remanufacturing/production quantities, the number of used products to collect and disassemble the inventory of recovered items and product flows between the various facilities in the supply chain. Wang and Hsu [16] proposed a generalized model for solving a closed loop logistics network in which the uncertainty is expressed by fuzzy numbers. They proposed an interval programming model by the defined means and mean square imprecision index obtained from the integrated information of all the level cuts of fuzzy numbers. The interval programming is resolved based on decision maker's preference and the solution obtained provides useful information on the expected solutions under a confidence level containing a degree of risk.

Zhang et al. [17] proposed an inexact reverse logistics model for municipal solid waste management systems (IRWM) in which waste managers, suppliers, industries and distributors were involved in strategic planning and operational execution through reverse logistics management. The model was applied in a classical municipal solid waste management case. Pishvaee et al. [18] proposed a robust optimization model to closed-loop supply chain network design under uncertainty. They developed a deterministic mixed-integer linear programming model for designing the network and presented its robust counterpart using the recent extensions in robust optimization theory. Liao and Rachmat [19] proposed a mathematical model for a multi-product reverse logistics for third party logistics (3PLs) by considering uncertain conditions in a multi-echelon network to minimize the total cost of the reverse logistics. The model is solved with LINGO. The model decreases the total cost of the reverse logistics managed by a 3PL by $13.8 \%$. Xanthopoulos et al. [20] proposed a single period stochastic inventory decision-making model that captures the trade-offs between inventory policies and disruption risks for unreliable (both un-capacitated and capacitated) dual sourcing reverse supply chain networks. They suggested that the model can be applied to a number of different scenarios including instances of disruptions to the collection of end-of-life products of the transport system and of the remanufacturing yield and capacity. Khajavi et al. [21] presented an integrated forward/reverse logistics network optimization model for multi-stage capacitated supply chain network. The model is proposed by formulating the generalized logistics network problem into a bi-objective mixed-integer programming model to minimize the total costs and maximize the responsiveness of the CLSC network simultaneously. Das and Chowdhury [22] proposed an integrated network design for reverse logistics to deal with optimal collection, recovery and quality based product-mix planning. They formulated a mixed integer programming model to maximize profit by considering the collection of returned products, the recovery of modules and the proportion of the product mix at different quality levels. They proposed the collection of end-of-life, defective products under warranty through retail outlets combined with the recovery of modules from the collected products using a network of recovery service providers. Pochampally and Gupta [23] proposed a quantitative decision making model to select efficient collection centers and to evaluate whether repairing an end-of-use product is more sensible than remanufacturing/recycling the product. They proposed a linear physical programming (LPP) model and employed Fuzzy logic and Bayesian updating to solve the problems. Piplani and Saraswat [24] adapted robust optimization approach to design service networks for reverse logistics. They proposed a mixed-integer linear programming (MILP) model to minimize the total cost subject to flow balance and logical constraints.

Das [25] proposed a mixed-integer programming (MIP) model for integrating reverse logistics into the strategic planning of a supply chain. They adopted an approach in the model that uses retail outlets as a two-way channel for making new products, collecting used/returned products and remarketing recovered products as a way of promoting an effective product recovery system in supply chain operation and optimizing costs. Nenes and Nikolaidis [26] presented a MILP model for optimizing the decisions of a remanufacturing company carry- 
ing out procurement, remanufacturing, salvaging and stocking of used products for multiple periods of time. Ozkir and Basligil [27] proposed modeling of product recovery processes in closed loop supply chain network design where a mixed integer linear programming model was applied to obtain CLSC network design in which the recovery process occurs in three different ways: material recovery, component recovery and product recovery. Alumur et al. [28] proposed a profit maximization modeling framework for reverse logistics network design. They presented a mixed-integer linear programming formulation which can incorporate most of the reverse network structures plausible in practice. A multi-period setting was considered to accommodate the future adjustments in the configuration and periodical changes in the network structure and capacities of the facilities. They proposed a multi commodity formulation and use of reverse bill of materials to identify the commonalities among different products and to track the product returns. They applied the model in the reverse logistics network design of a washing machine and tumble drier case study in Germany and illustrated the potential benefits of the proposed dynamic model. Mahmoudi et al. [29] proposed a mathematical model for optimizing a reverse supply chain including transportation, operation, maintenance and remanufacturing costs. They presented an integer linear programming model for multi-layer, multi product reverse supply chain that minimizes the products and parts transportation costs among centers and also sites launch, operation parts, maintenance and remanufacturing costs at the same time.

Donmez and Turkay [30] presented a mixed-integer linear programming model for the design of reverse logistics network for collecting, sorting, exporting, recycling and disposing of waste batteries at a landfill area. Ramezani et al. [31] presented a new multi-objective stochastic model for a forward/reverse logistic network design with responsiveness and quality level. They included three echelons in forward flow, viz. suppliers, plants and distribution centers and two echelons in the backward flow, viz. collection centers and disposal centers. They evaluated the systematic supply chain configuration maximizing the profit, customer responsiveness and quality to achieve the objectives of the network. They obtained Pareto optimal solutions and computed their financial risk to show the trade-offs between the objectives. Keyvanshokooh et al. [32] developed a dynamic pricing approach for returned products in integrated forward/reverse logistics network design in order to determine the acquisition price of the used products to find out the percentage of returned products collected from customer zones. They developed a mixed integer linear programming to consider the dynamic pricing for used products, supply chain network configuration and inventory decisions. Vahdani et al. [33] proposed a Fuzzy possibilistic-queuing model for a reliable design of a logistics network under uncertainty. The bi-objective model was designed to minimize the total cost and the expected transportation costs after failures of bi-directional facilities of the logistics network. They solved the model by combining queuing theory, fuzzy probabilistic programming and fuzzy multi-objective programming. Hafeti and Jolai [34] proposed a robust and reliable network design for forward-reverse logistics design which simultaneously takes care of uncertain parameters and facility disruptions in the network. They proposed a mixed integer linear programming model with augmented p-robust constraints considered to control the reliability of the network during disruptions thereby reducing the nominal cost and disruptions risks. Amin and Zhang [35] presented a multi-objective facility location model for closedloop supply chain network under uncertain demand and return. They investigated the CLSC network which includes multiple plants, collection centers, demand markets and products. They proposed a mixed integer linear programming model that minimizes the total cost. They also extended the model to include the environmental factors by weighed sums and constraint methods. They also investigated the impact of demand and return uncertainties on the network configuration by stochastic programming. Cardoso et al. [36] developed a mixed integer linear programming for the design and planning of supply chains with reverse flows by simultaneously considering the production, distribution and reverse logistics activities for which the product demand is uncertain. The model defines the maximization of the expected net present value and provides details on sizing and location of plants, warehouses and retailers, definition of processes to install, establishment of forward and reverse flows and inventory levels to achieve. Lizarazo et al. [37] proposed a mathematical model to represent the dynamic interaction between the forward flow and the reverse flow of a closed loop supply chain framework in the agro-industrial sector. They considered energy, cost and economic profits in the objective function and proposed different implementation scenarios of recovery processes. They evaluated the interactions between the forward and reverse flows in supply chain and analyzed the results using statistical tools, and showed that the simultaneous analysis of forward and reverse flows positively impact the net economic profits in the complex supply chain of agro-industrial sector. Mahmoudzadeh et al. [38] developed a third party reverse logistics network for end of life vehicles in Iran. They formulated the model using MILP to determine the optimal locations 
of scrap yards over the country, their optimal allocations and material flows. They categorized the ELVs into three quality levels with different output material streams and analyzed two managerial scenarios in addition to the current situation to provide insights on future situations. It is found from the result that most of the scrap yards are opened with serving only one or two quality levels. Rosa et al. [39] presented a robust sustainable bi-directional logistics net-work design under uncertainty which handles a network of multiple supply stages, including production allocations, uncertain data development, facility locations and flexible capacity adjustments. They extended the location and capacity problem by including the decision on the type of depot to install. Ozceylan et al. [40] presented an integrated model that optimizes the strategic decisions related to the quantity of goods flowing on the forward and reverse chains, and the tactical decisions on balancing disassembly lines in the reverse chain, with an objective to minimize costs of transportation, purchasing, refurbishing and operating the disassembly work-stations. They developed a mixed integer nonlinear programming (MINLP) to solve the problem and presented the results.

From the literature, it is observed that many researchers have contributed to the development of mathematical models for the reverse logistics problem as well as closed loop SCM involving reverse logistics. In future, goal programming models may be attempted to optimize multi-objectives with certain achievement levels for each goal.

\subsection{Branch and Bound Algorithm}

Branch and bound method is an optimization method, which is an improved method over complete enumeration method. In this method, certain solution nodes are eliminated based on either lower bound or upper bound depending on minimization or maximization objective of the problem, respectively. This section gives the review of literature of the application of branch and bound method applied to closed loop supply chain network.

Salema et al. [41] presented a strategic and tactical model for closed loop supply chain. They integrated the strategic network design decisions with the tactical decisions like production, storage and distribution planning and achieved the integration by considering the micro and macro time scales. They also formulated a mixed integer linear programming and solved the model using standard branch and bound techniques. Only very few research is carried out using branch and bound technique. Future research may be directed to develop branch and bound algorithm with stronger cuts.

\subsection{Heuristics}

The problem of network design for the closed loop as well as reverse logistics supply chain comes under combinatorial category, finding the optimal solution using any mathematical model or complete enumeration or branch and bound technique or any other exact algorithm will take enormous time. Hence, the use of heuristics is justified for this problem. This section gives a review of literature of heuristics applied to the design of reverse logistics as well as closed loop supply chain networks to find the best near optimal solution if not optimal.

Chen et al. [42] presented a model that characterizes, formulates and solves the reverse logistic recycling flow equilibrium (RLRFE) problem which is concerned with the recycling channel consists of multi-tiered network to process the recycled material flows from recyclable collectors, processors to either landfills or demand markets. A nested diagonalization solution (ND) algorithm is developed to solve this problem. Alshamrani et al. [43] worked on the simultaneous design of delivery routes and return strategies of a reverse logistics network and formulated a pick up strategy to determine the quantity of the returning materials to be picked up at each stop. A heuristic procedure was developed involving a weighted leveling policy for return decisions as this integrated and dynamic planning problem was very intense to compute. The proposed algorithm is a modified OR-opt procedure. OR-opt procedure is an optimization procedure and OR in it is the name of its author. Lu and Bostel [44] presented a two level location model with three types of facility in a specific reverse logistics system named Remanufacturing Network (RMN) in which the forward and reverse flows are simultaneously considered. An algorithm based on the Lagrangian heuristic approach was proposed to solve the problem. In future the work can be extended to facility location problems with capacity and for other problems in reverse logistics systems. Du and Evans [45] designed a bi-objective logistics network for post-sale service to address the minimization of the overall costs and minimization of the total tardiness of cycle time. They adopted a solution approach consists of three algorithms: scatter search, the dual simplex method and the constraint method for solving this bi-objective 
model. Both installation costs and transportation cost in the first objective function involve in the trade-off relationship with the second objective. It is also found that the optimization for the first objective function leads to a centralized network structure and that of the second objective function leads to a decentralized network structure. Lee and Dong [46] adopted a heuristic approach to logistics network design for end of lease computer products recovery. They developed first, a mathematical model for the integration of forward and reverse distribution network design and the locations of facilities jointly used by forward and reverse logistics operations. Then they developed a two-stage heuristic algorithm as the first attempt in solving the integrated forward and reverse logistics network design problem using meta-heuristics. A tabu search is also applied to obtain the improved solution of shipping the returned products.

Wollenweber [47] presented a model and heuristic approach for a multi stage facility location problem with staircase costs and splitting of commodities. The author proposed a two-phase heuristic solution approach in which the greedy construction heuristics utilizes the solution obtained by the LP-relaxation of the problem. The author combined ADD, DROP and SWAP neighborhoods with a diversification strategy to a Variable Descent (VND) and to a Variable Neighborhood Search (VNS) approach in the improvement heuristics. Pishvaee et al. [48] proposed a model for integrated logistic network design to address the issues due to increasing network costs and network responsiveness in supply chain and reverse logistics. They presented a bi-objective mixed integer non-linear programming (MINLP) model for the integrated forward and reverse logistics network design. The researchers designed a multi-objective memetic algorithm with dynamic local search mechanism (MOMA) to solve the model with non-dominated set of solutions. Pishvaee and Torabi [49] proposed a bi-objective possibilistic mixed integer linear programming model for a closed-loop supply chain network design under uncertainty. The model integrating the forward-reverse supply chain networks, applies the strategic network design decisions along with tactical material flow to avoid the sub-optimalities led from separated design in both parts. They developed an interactive fuzzy solution approach by combining a number of solution approaches from the recent literatures, for solving the proposed model. Wang and Hsu [50] investigated the integration of forward and reverse logistics, and proposed a closed loop model for the logistics planning by formulating a cyclic logistics network problem into an integer linear programming model. As the model is NP hard in nature and complicated to solve, an efficient algorithm was proposed based on a determinant encoding approach, to revise the existing spanning-tree based genetic algorithm. The researchers evaluated the algorithm, compared with LINGO and CPLEX for its accuracy, capability and efficiency and reported the results. Eskandarpur et al. [51] investigated the designing of a multi-product four layer post sales reverse logistics network operated by a 3PL. They proposed a bi-objective MILP model to minimize network design costs and the total weighted tardiness of returning products to customers. They suggested a multi-start variable neighbourhood search to incorporate nine neighbourhood structure and three new encoding-decoding mechanisms to solve the model. They also employed a fitness landscape measure to select an effective neighbourhood order for the variable neighbourhood search. The experiments and the results show that the proposed model finds better Pareto optimal sets and solutions than that of the original priority method. Eskandarpur et al. [52] proposed a multi objective post sales network design model to minimize total fixed and variable costs, total tardiness and environmental pollution. They developed a parallel multi-objective heuristic based on variable neighbourhood search (VNS) to tackle the model and to find Pareto optimal solutions. They compared the efficiency of the proposed method with an available efficient multi-objective memetic algorithm (MOMA) and compared the results with those of branch and bound methods of two commercial optimization packages for small and medium sized instances. They demonstrated the superiority of the proposed algorithm for its solution quality and computational time over MOMA as well as the single thread and multi-thread branch and bound methods. They also compared the heuristic with a standard VNS and demonstrated the success of parallelization in exploring solution space, improving number and quality of Pareto-optimal solutions. Devika et al. [53] presented a sustainable closed loop supply chain network design to cover the gap in the quantitative modeling by considering the social impacts, environmental impacts and economic impacts in the network design problem. They developed three new hybrid metaheuristic methods based on adapted imperialist competitive algorithms and variable neighbourhood research, to solve this NP hard problem. They compared the algorithms with each other and also with other strong algorithms to assess the efficiency and effectiveness of the proposed algorithms. It is found that the nested approach provides better solutions than the others and the applicability of the approach is demonstrated with a case study of a glass industry.

Many researchers have contributed to heuristic development of reverse logistics as well as closed loop SCM involving reverse logistics in terms of network design and optimization. 


\subsection{Genetic Algorithms}

As stated earlier, the problem of supply chain network design comes under combinatorial category. So, the use of genetic algorithm will give better solution when compared to heuristic approaches. The genetic algorithm is based on a natural selection process that mimics the biological evolution for solving both constrained and unconstrained optimization problems. The algorithm repeatedly modifies a population of individual solutions (called chromosomes). At each step, the genetic algorithm randomly selects individuals from the current population and uses them as parents to produce the children for the next generation. Over successive generations, the population evolves toward an optimal solution. In this section, the review of literature of the application of GA based heuristics to the design of supply chain networks is presented.

Ko and Evans [54] developed an optimization model and associated algorithm to design an integrated logistics network for 3PL providers. They considered the simultaneous flow of forward and reverse logistics network and presented a mixed integer nonlinear programming model which is a multi-period, two-echelon, multicommodity, capacitated network design problem. The proposed method to solve the problem is a GA-based heuristic with genetic operations and transshipment algorithm. Min et al. [55] proposed a mixed integer programming model and a genetic algorithm that can solve the reverse logistics problem involving the location and allocation of repair facilities for 3PLs. They considered the savings due to the use of existing warehouses as repair facilities and costs associated with location or expansion. The model deals with multi-echelon reverse logistics configurations that consider both direct product returns from customers to manufacturing plants and indirect returns through either repair facilities or regional warehouses. Lee and Chan [56] proposed a genetic algorithm to determine the appropriate locations for collection points to maximize the coverage of customers. They also developed a model to demonstrate the benefits of using a computational intelligence technique and RFID to form an integrated model for optimizing the coverage of product returns. The simulation results showed the ability of GA to produce good quality solutions in terms of coverage of collection points by choosing suitable locations for collection points with the support of RFID to detect the quantity of returned products so as to increase efficiency of logistics operations. Lee et al. [57] proposed a model for optimization of reverse logistics network using hybrid genetic algorithm. They formulated the model for remanufacturing system as three stage logistics network and considered a multi-stage, multi product model in order to minimize the total cost to reverse logistics shipping cost and fixed opening cost of the disassembly centers and processing centers. They proposed a genetic algorithm with priority-based encoding method consisting of $1^{\text {st }}$ and $2^{\text {nd }}$ stages combined, a new crossover operator called as weight mapping crossover (WMX). They applied a heuristic in the $3^{\text {rd }}$ stage to transportation of parts from processing center to manufacturer. They showed the effectiveness and efficiency of the model by comparing the end results with recent researches. Fakhrzad and Moobed [58] formulated a mathematical model to address the reverse logistics facility location and integration problem. They developed a Genetic algorithm for solving the problem. The results show that the best solutions are obtained when the free space of distribution center is used for collecting/inspecting used products in cities, without recycling/disposal centers. Trappey et al. [59] proposed a fuzzy cognitive model for constructing a reverse logistics network which integrates RFID technology to collect real time data from daily operations for network performance forecasting and decision support. The dynamic performance of the forward and reverse logistics network with uncertainty was evaluated using a genetic algorithm. Diabat et al. [60] developed a multi-echelon reverse logistics network for product returns to minimize the total reverse logistics cost, which includes the costs of renting, carrying inventory, handling materials, set up and shipping. They developed a mixed integer non-linear programming (MINLP) model to arrive at the number and location of initial collection points and centralized return centers required for an effective return and collection system, and also the maximum holding time (collection frequency) for aggregation of small volumes of returned products into large shipments. They implemented and compared the genetic algorithm and artificial immune system for solving the model and demonstrated the application of the model with an example.

Future research may be directed to develop different crossover methods for genetic algorithm and study their effects on solution accuracy of the problem.

\subsection{Simulated Annealing Algorithm}

Simulated annealing (SA) algorithm is based on the process of annealing which is applied to heat treatment process in industries to relive internal stress and strain of forged components and allied components to soften its 
hardness. This approach helps analyst find global optimum solution for combinatorial problems like the design of supply chain networks. This section presents its review. Lee and Dong [61] explored a stochastic approach for the dynamic reverse logistics network design under uncertainty. They developed a two stage stochastic programming model which is based on SA based heuristic algorithm. It provides an efficient framework for identifying and statistically solving the large scale dynamic network problems. Pishvaee et al. [62] worked on a reverse logistics network design using simulated annealing. They developed a multi integer linear programming (MILP) model for multi stage reverse logistics network design for reducing the total costs which include fixed opening costs and transportation costs. They used a SA algorithm with dynamic neighborhood search mechanism to find the optimal solution of the model for large-sized problems. The model is applicable for single product network with deterministic returned products. The future research could be carried out for multi-product network with uncertainty in returns, using other meta-heuristic algorithms like tabu search and scatter search. Subramanian et al. [63] considered a closed loop supply chain and addressed the issues of designing the network and optimizing the distribution. They considered four variants of the problems and modeled it as an integer linear programming. They developed a constructive heuristic based on Vogel's approximation method-total opportunity cost method to provide good initial solutions to a priority based simulated annealing heuristic to accelerate its convergence. They carried out trails using a set of hypothetical datasets which have yielded encouraging results.

More research may be carried out using simulated annealing algorithm with innovative perturbation schemes for this problem.

\subsection{Petri Net Algorithm}

Petri net is a network based optimization algorithm. This section gives its review of literature applied to the design of supply chain networks. Hanafi et al. [64] presented reverse logistics strategy for end of life products which is an integrated collection strategy which includes a Fuzzy colored Petri net forecasting method and collection network model to collect EOL products. The strategy is tested using a case study on mobile phone collection in Australia. From the results it is found that the best strategy in a particular location can be determined by providing demographic data and historical sales of a relevant product in that location and also found that the best strategy suits for one location might be different to other locations. Very little work is carried out using this approach for this problem.

\subsection{Analytic Hierarchy Process (AHP)}

AHP is an approach which forms relative importance indices among several options of evaluation criteria. This section gives its review of literature for the design of supply chain networks.

Kannan [65] has proposed a structured model for evaluating and selecting the best third party reverse logistics provider (3PRLP) under fuzzy environment for the battery industry. In this paper, the multi-criteria decision-making tools such as analytic hierarchy process (AHP) and fuzzy analytic hierarchy process (FAHP) are adopted to solve the problem of selection of 3PRLP. A case study applied to battery industry is also presented in this paper. It is observed that few researches have been carried out using this approach for this problem.

\subsection{Simulation Approaches}

Most of the real life problems have data which are stochastic in nature. For such environment, simulation gives average measure of performance, based on which effective and efficient decision can be made. This section gives the review of literature of the applications of simulation to the design of supply chain networks. Tonanont et al. [66] presented a simulation model for reverse logistics optimization with data envelopment analysis for carpet recycling in CLSC. The proposed simulation model for CLSC design was adapted from Soto's model. It designs and evaluates the efficiency of CLSC within the range of specified parameters and provides the opportunity to improve efficiency by varying significant parameters. Suryabatmaz et al. [67] presented a two hybrid simulation-analytical modeling approaches for the reverse logistics network design of a 3PL provider. The first one is an adaptation of a problem specific approach proposed in the literature and the second one is the development of a generic approach in which instead of exchanging problem specific parameters between the analytical and simulation model, the interacting is governed by reflecting the impact of uncertainty obtained via simu- 
lation to the objective function of the analytical model. Simulation is the last resort for any problem, if an investigator is unable to tackle the problem using standard models. So, this may be given importance in future researches.

\subsection{General Approaches}

The approaches which are not included under any of the above eight categories are included under general approaches and its review of literature is given here.

Savaskan et al. [68] proposed the closed loop supply chain models with product remanufacturing and addressed the problem of choosing the suitable reverse channel structure for the collection of used products from customers. They suggested three options for collecting the products to the manufacturer, viz. the manufacturer can collect directly from the customers, the manufacturer can induce the collection through an existing retailer in the distribution channel by providing suitable incentives or the manufacturer can subcontract the collection activity to a third party. They applied the model on the three options as decentralized decision making system led by the manufacturer. They found that the second option i.e. the collection of products through retailer who is closer to the customers is the most effective one for the manufacturer. Srivastava and Srivastava [69] presented a framework for reverse logistics to manage product returns from select categories of products in India. They developed a conceptual model with integrated modeling framework borrowed from the existing literatures and industry practices. The model utilized ownership data, average life cycle of the products, past sales, forecasted demand and likely impact of environmental policy measures to estimate return flows. They conducted survey through informal interviews with 84 stake holders to estimate the significant parameters and used software packages, decomposition methods and heuristics to solve the model. The integrated framework helped in estimating returns for select categories of products and managing them for a given time period under various strategic, operational and customer service related constraints. Roy et al. [70] presented the reverse logistics networks and governance structures which include recycling of used tires, empty beer bottles, used paint and paper products. They involved the government organizations and dedicated third parties in some of the case studies to govern the reverse logistics networks and to modify the natural relationships normally observed in the traditional supply chains.

\section{Conclusion}

Reverse logistics plays a vital role in terms of minimizing the logistics cost and satisfying the customer needs with lower cost. In this paper, the design of logistics network for reverse logistics as well as of closed loop SCM involving reverse logistics is considered. A comprehensive review of literature is presented on the proposed problem based on the methods to provide solution, viz. models, branch and bound algorithms, heuristics, genetic algorithms, simulated annealing algorithms, Petri net algorithms, analytic hierarchy process (AHP), simulation approaches and general approaches. From the literature, it is clear that many of the meta-heuristics such as ACO algorithms, PSO algorithms GRASP, Firefly algorithm, etc. are not tried for this problem. So, future researches may be carried out in this direction. The review of literature presented in this paper will be more useful for the researchers to identify potential problems and related solution procedures for the reverse logistics network design.

\section{References}

[1] Krikke, H., Ruwaardz, J.B. and Wassenhove, L.N.V. (2003) Concurrent Product and Closed-Loop Supply Chain Design with an Application to Refrigerators. International Journal of Production Research, 41, 3689-3719. http://dx.doi.org/10.1080/0020754031000120087

[2] Schultmann, F., Zumkeller, M. and Rentz, O. (2006) Modeling Reverse Logistic Tasks within Closed-Loop Supply Chains: An Example from the Automotive Industry. European Journal of Operational Research, 171, 1033-1050. http://dx.doi.org/10.1016/j.ejor.2005.01.016

[3] Salema, MI., Povoa, APB. and Novais, AQ. (2006) A Warehouse-Based Design Model for Reverse Logistics. Journal of the Operational Research Society, 57, 615-629. http://dx.doi.org/10.1057/palgrave.jors.2602035

[4] Savaskan, R.C. and Wassanhove, L.N.V. (2006) Reverse Channel Design: The Case of Competing Retailers. Management Science, 52, 1-14. http://dx.doi.org/10.1287/mnsc.1050.0454

[5] Salema, M.I.G., Povoa, A.P.B. and Novais, A.Q. (2007) An Optimization Model for the Design of a Capacitated MultiProduct Reverse Logistics Network with Uncertainty. European Journal of Operational Research, 179, 1063-1077. http://dx.doi.org/10.1016/j.ejor.2005.05.032 
[6] Ondemir, O. and Gupta, S.M. (2008) Selection of Collection Centers for Reverse Logistic Networks. Northeast Decision Sciences Institute Proceedings, Newyork, 28-30 March 2008, 592-596.

[7] Mansour, S. and Zarei, M. (2008) A Multi-Period Reverse Logistics Optimization Model for End-of-Life Vehicles Recovery Based on EU Directive. International Journal of Computer Integrated Manufacturing, 21, 764-777. http://dx.doi.org/10.1080/09511920701685325

[8] Demirel, N.O. and Gökçen, H. (2008) A Mixed Integer Programming Model for Remanufacturing in Reverse Logistics Environment. International Journal of Advanced Manufacturing Technology, 39, 1197-1206. http://dx.doi.org/10.1007/s00170-007-1290-7

[9] Lashkari, R.S. and Zhang, H. (2008) Modeling and Analysis of a Reverse Supply Chain Network for Lead-Acid Battery Manufacturing. Operations and Supply Chain Management, 1, 43-56.

[10] Barker, T.J. and Zabinsky, Z.B. (2008) Reverse Logistics Network Design: A Framework for Decision Making. Proceedings of the 2008 Industrial Engineering Research Conference, Vancouver, B.C., 7-21 May 2008, 1290-1295.

[11] Reynaldo, C.R. and Ertel, J. (2009) Reverse Logistics Network Design for the Collection of End-of-Life Vehicles in Mexico. European Journal of Operational Research, 196, 930-939. http://dx.doi.org/10.1016/j.ejor.2008.04.041

[12] Kannan, G., Pokharel, S. and Sasi, Kumar, P. (2009) A Hybrid Approach Using ISM and Fuzzy TOPSIS for the Selection of Reverse Logistics Provider. Resources, Conservation and Recycling, 54, 28-36. http://dx.doi.org/10.1016/j.resconrec.2009.06.004

[13] Mutha, A. and Pokharel, S. (2009) Strategic Network Design for Reverse Logistics and Remanufacturing Using New and Old Product Modules. Computers \& Industrial Engineering, 56, 334-346. http://dx.doi.org/10.1016/j.cie.2008.06.006

[14] El-Sayed, M., Afia, N. and El-Kharbotly, A. (2010) A Stochastic Model for Forward-Reverse Logistics Network Design under Risk. Computers \& Industrial Engineering, 58, 423-431. http://dx.doi.org/10.1016/j.cie.2008.09.040

[15] Dahel, N.E. (2010) Modeling Supply Chain Network Design and Product Recovery Planning under Uncertainty. Northeast Decision Sciences Institute Proceedings, Virginia, 26-28 March 2010, 714-719.

[16] Wang, H.F. and Hsu, H.W. (2010) Resolution of an Uncertain Closed-Loop Logistics Model: An Application to Fuzzy Linear Programs with Risk Analysis. Journal of Environmental Management, 91, 2148-2162. http://dx.doi.org/10.1016/j.jenvman.2010.05.009

[17] Zhang, Y.M., Huang, G.H. and Heb, L. (2011) An Inexact Reverse Logistics Model for Municipal Solid Waste Management Systems. Journal of Environmental Management, 92, 522-530. http://dx.doi.org/10.1016/j.jenvman.2010.09.011

[18] Pishvaee, M.S., Rabbani, M. and Torabi, S.A. (2011) A Robust Optimization Approach to Closed-Loop Supply Chain Network Design under Uncertainty. Applied Mathematical Modelling, 35, 637-649. http://dx.doi.org/10.1016/j.apm.2010.07.013

[19] Liao, T.Y. and Rachmat, A. (2011) A Multi-Product Reverse Logistics Model for Third Party Logistics. International Conference on Modeling, Simulation and Control, IPCSIT, IACSIT Press, Singapore.

[20] Xanthopoulos, A., Vlachos, D. and Iakovou, E. (2011) Optimal Sourcing Decisions for Unreliable Reverse Supply Chains. Asia-Pacific Journal of Operational Research, 28, 125-146. http://dx.doi.org/10.1142/S0217595911003090

[21] Khajavi, L.T., Seyed-Hosseini, S.M. and Makui, A. (2011) An Integrated Forward/Reverse Logistics Network Optimization Model for Multi-Stage Capacitated Supply Chain. iBusiness, 3, 229-235.

[22] Das, K. and Chowdhury, A.H. (2011) Designing a Reverse Logistics Network for Optimal Collection, Recovery and Quality Based Product-Mix Planning. International Journal of Production Economics, 135, 209-221. http://dx.doi.org/10.1016/j.ijpe.2011.07.010

[23] Pochampally, K.K. and Gupta, S.M. (2012) Use of Linear Physical Programming and Bayesian Updating for Design Issues in Reverse Logistics. International Journal of Production Research, 50, 1349-1359. http://dx.doi.org/10.1080/00207543.2011.571933

[24] Piplani, R. and Saraswat, A. (2012) Robust Optimization Approach to the Design of Service Networks for Reverse Logistics. International Journal of Production Research, 50, 1424-1437. http://dx.doi.org/10.1080/00207543.2011.571942

[25] Das, K. (2012) Integrating Reverse Logistics into the Strategic Planning of a Supply Chain. International Journal of Production Research, 50, 1438-1456. http://dx.doi.org/10.1080/00207543.2011.571944

[26] Nenes, G. and Nikolaidis, Y. (2012) A Multi-Period Model for Managing Used Product Returns. International Journal of Production Research, 50, 1360-1376. http://dx.doi.org/10.1080/00207543.2011.609650

[27] Ozkir, V. and Basligil, H. (2012) Modelling Product-Recovery Processes in Closed-Loop Supply-Chain Network Design. International Journal of Production Research, 50, 2218-2233. http://dx.doi.org/10.1080/00207543.2011.575092 
[28] Alumur, S.A., Nickel, S., Gama, F.S.D. and Verter, V. (2012) Multi-Period Reverse Logistics Network Design. European Journal of Operational Research, 220, 67-78. http://dx.doi.org/10.1016/j.ejor.2011.12.045

[29] Mahmoudi, H., Fazlollahtabar, H. and Mahdavi, I. (2013) Mathematical Modeling for Minimizing Costs in a Multilayer Multi-Product Reverse Supply Chain. Industrial Engineering \& Management, 2, 1-6.

[30] Donmez, I. and Turkay, M. (2013) Design of Reverse Logistics Network for Waste Batteries with an Application in Turkey. Chemical Engineering Transactions, 35, 1393-1398.

[31] Ramezani, M., Bashiri, M. and Moghaddam, R.T. (2013) A New Multi-Objective Stochastic Model for a Forward/Reverse Logistic Network Design with Responsiveness and Quality Level. Applied Mathematical Modeling, 37, 328-344. http://dx.doi.org/10.1016/j.apm.2012.02.032

[32] Keyvanshokooh, E., Fattahi, M., Hosseini, S.M.S. and Moghaddam, R.T. (2013) A Dynamic Pricing Approach for Returned Products in Integrated Forward/Reverse Logistics Network Design. Applied Mathematical Modeling, 37, 1018210202. http://dx.doi.org/10.1016/j.apm.2013.05.042

[33] Vahdani, B., Mogaddham, R.T. and Jolai, F. (2013) Reliable Design of a Logistics Network under Uncertainty: A Fuzzy Possibilistic-Queuing Model. Applied Mathematical Modeling, 37, 3254-3268. http://dx.doi.org/10.1016/j.apm.2012.07.021

[34] Hafeti, S.M. and Jolai, F. (2013) Robust and Reliable Forward-Reverse Logistics Network Design under Demand Uncertainty and Facility Disruptions. Applied Mathematical Modeling, 38, 9-10.

[35] Amin, S.H. and Zhang, G.Q. (2013) A Multi-Objective Facility Location Model for Closed Loop Supply Chain Network under Uncertain Demand and Return. Applied Mathematical Modeling, 37, 4165-4176. http://dx.doi.org/10.1016/j.apm.2012.09.039

[36] Cardoso, S.R., Barbosa-Póvoa, A.P.F.D. and Relvas, S. (2013) Design and Planning of Supply Chains with Integration of Reverse Logistics Activities under Demand Uncertainty. European Journal of Operational Research, 226, 436-451. http://dx.doi.org/10.1016/j.ejor.2012.11.035

[37] Lizarazo, E.H.A., Torres, J.R.M. and Franco, E.G. (2013) Modeling Reverse Logistics Process in the Agro-Industrial Sector: The Case of the Palm Oil Supply Chain. Applied Mathematical Modeling, 37, 9652-9664. http://dx.doi.org/10.1016/j.apm.2013.05.015

[38] Mahmoudzadeh, M., Mansour, S. and Karimi, B. (2013) To Develop a Third Party Reverse Logistics Network for Endof-Life Vehicles in Iran. Resources, Conservation and Recycling, 78, 1-14. http://dx.doi.org/10.1016/j.resconrec.2013.06.006

[39] De Rosa, V., Gebhard, M., Hartmann, E. and Wollenweber, J. (2013) Robust Sustainable Bi-Directional Logistics Network Design under Uncertainty. International Journal of Production Economics, 145, 184-198. http://dx.doi.org/10.1016/j.ijpe.2013.04.033

[40] Ozceylan, E., Paksoy, T. and Bektas, T. (2014) Modeling and Optimizing the Integrated Problem of Closed-Loop Supply Chain Network Design and Disassembly Line Balancing. Transportation Research Part E, 61,142-164. http://dx.doi.org/10.1016/j.tre.2013.11.001

[41] Salema, M.I.G., Povoa, A.P.B. and Novais, A.Q. (2009) A Strategic and Tactical Model for Closed-Loop Supply Chains. OR Spectrum, 31, 573-599. http://dx.doi.org/10.1007/s00291-008-0160-5

[42] Chen, H.K., Chou, H.W. and Chiu, Y.C. (2007) On the Modeling and Solution Algorithm for the Reverse Logistics Recycling Flow Equilibrium Problem. Transportation Research Part C, 15, 218-234. http://dx.doi.org/10.1016/j.trc.2007.05.001

[43] Alshamrani, A., Mathurb, K. and Balloub, R.H. (2007) Reverse Logistics: Simultaneous Design of Delivery Routes and Returns Strategies. Computers \& Operations Research, 34, 595-619. http://dx.doi.org/10.1016/j.cor.2005.03.015

[44] Lu, Z. and Bostel, N. (2007) A Facility Location Model for Logistics Systems Including Reverse Flows: The Case of Remanufacturing Activities. Computers \& Operations Research, 34, 299-323. http://dx.doi.org/10.1016/j.cor.2005.03.002

[45] Du, F. and Evans, G.W. (2008) A Bi-Objective Reverse Logistics Network Analysis for Post-Sale Service. Computers \& Operations Research, 35, 2617-2634. http://dx.doi.org/10.1016/j.cor.2006.12.020

[46] Lee, D.H. and Dong, M. (2008) A Heuristic Approach to Logistics Network Design for End-of-Lease Computer Products Recovery. Transportation Research Part E, 44, 455-474. http://dx.doi.org/10.1016/j.tre.2006.11.003

[47] Wollenweber, J. (2008) A Multi-Stage Facility Location Problem with Staircase Costs and Splitting of Commodities: Model, Heuristic Approach and Application. OR Spectrum, 30, 655-673. http://dx.doi.org/10.1007/s00291-007-0114-3

[48] Pishvaee, M.S., Farahani, R.Z. and Dullaert, W. (2010) A Memetic Algorithm for Bi-Objective Integrated Forward/Reverse Logistics Network Design. Computers \& Operations Research, 37, 1100-1112. http://dx.doi.org/10.1016/j.cor.2009.09.018 
[49] Pishvaee, M.S. and Torabi, S.A. (2010) A Possibilistic Programming Approach for Closed-Loop Supply Chain Network Design under Uncertainty. Fuzzy Sets and Systems, 161, 2668-2683. http://dx.doi.org/10.1016/j.fss.2010.04.010

[50] Wang, H.F. and Hsu, H.W. (2010) A Closed-Loop Logistic Model with a Spanning-Tree Based Genetic Algorithm. Computers \& Operations Research, 37, 376-389. http://dx.doi.org/10.1016/j.cor.2009.06.001

[51] Eskandarpur, M., Nikbakhsh, E. and Zegordi, S.H. (2013) Variable Neighborhood Search for the Bi-Objective Post Sales Network Design Problem: A Fitness Landscape Analysis. Computers \& Operations Research, in press. http://dx.doi.org/10.1016/j.cor.2013.06.002

[52] Eskandarpur, M., Zegordi, S.H. and Nikbakhsh, E. (2013) A Parallel Variable Neighborhood Search for the MultiObjective Sustainable Post Sales Network Design Problem. International Journal of Production Economics, 145, 117131. http://dx.doi.org/10.1016/j.ijpe.2012.10.013

[53] Devika, K., Jafarian, A. and Nourbakhash, V. (2014) Designing a Sustainable Closed-Loop Supply Chain Network Based on Triple Bottom Line Approach: A Comparison of Metaheuristics Hybridization Techniques. European Journal of Operational Research, 235, 594-615. http://dx.doi.org/10.1016/j.ejor.2013.12.032

[54] Ko, H.J. and Evans, G.W. (2007) A Genetic Algorithm-Based Heuristic for the Dynamic Integrated Forward/Reverse Logistics Network for 3PLs. Computers \& Operations Research, 34, 346-366. http://dx.doi.org/10.1016/j.cor.2005.03.004

[55] Min, H., Ko, H.J. and James, R. (2008) The Dynamic Design of a Reverse Logistics Network from the Perspective of Third-Party Logistics Service Providers. International Journal of Production Economics, 113, 176-192. http://dx.doi.org/10.1016/j.ijpe.2007.01.017

[56] Lee, C.K.M. and Chan, T.M. (2009) Development of RFID-Based Reverse Logistics System. Expert Systems with Applications, 36, 9299-9307. http://dx.doi.org/10.1016/j.eswa.2008.12.002

[57] Lee, J.E., Gen, M. and Rhee, K.G. (2009) Network Model and Optimization of Reverse Logistics by Hybrid Genetic Algorithm. Computers \& Industrial Engineering, 56, 951-964. http://dx.doi.org/10.1016/j.cie.2008.09.021

[58] Fakhrzad, M.B. and Moobed, M. (2010) A GA Model Development for Decision Making under Reverse Logistics. International Journal of Industrial Engineering \& Production Research, 21, 211-220.

[59] Trappey, A.J.C., Charles, V., Trappey, C.V. and Wub, C.R. (2010) Genetic Algorithm Dynamic Performance Evaluation for RFID Reverse Logistic Management. Expert Systems with Applications, 37, 7329-7335. http://dx.doi.org/10.1016/j.eswa.2010.04.026

[60] Diabet, A., Kannan, D., Kaliyan, M. and Svetinovic, D. (2013) An Optimization Model for Product Returns Using Genetic Algorithms and Artificial Immune System. Resources, Conservation and Recycling, 74, 156-169. http://dx.doi.org/10.1016/j.resconrec.2012.12.010

[61] Lee, D.H. and Dong, M. (2009) Dynamic Network Design for Reverse Logistics Operations under Uncertainty. Transportation Research Part E, 45, 61-71. http://dx.doi.org/10.1016/j.tre.2008.08.002

[62] Pishvaee, M.S., Kianfar, K. and Karimi, B. (2010) Reverse Logistics Network Design Using Simulated Annealing. International Journal of Advanced Manufacturing Technology, 47, 269-281. http://dx.doi.org/10.1007/s00170-009-2194-5

[63] Subramanian, P., Ramkumar, N., Narendran, T.T. and Ganesh, K. (2013) PRISM: Priority Based Simulated Annealing for a Closed Loop Supply Chain Network Design Problem. Applied Soft Computing, 13, 1121-1135. http://dx.doi.org/10.1016/j.asoc.2012.10.004

[64] Hanafi, J., Kara, S. and Kaebernick, H. (2008) Reverse Logistics Strategies for End-of-Life Products. The International Journal of Logistics Management, 19, 367-388. http://dx.doi.org/10.1108/09574090810919206

[65] Kannan, G. (2009) Fuzzy Approach for the Selection of Third Party Reverse Logistics Provider. Asia Pacific Journal of Marketing and Logistics, 21, 397-416. http://dx.doi.org/10.1108/13555850910973865

[66] Tonanont, A., Yimsiri, S. and Rogers, K.J. (2009) Reverse Logistics Optimization with Data Envelopment Analysis. Proceedings of 2009 Industrial Engineering Research Conference, Miami, 30 May-3 June 2009, 1268-1273.

[67] Suryabatmaz, A.C., Altekin, F.T. and Sahin, G. (2014) Hybrid Simulation-Analytical Modeling Approaches for the Reverse Logistics Network Design of a Third-Party Logistics Provider. Computers and Industrial Engineering, 70, 7489. http://dx.doi.org/10.1016/j.cie.2014.01.004

[68] Savaskan, R.C., Bhattacharya, S. and Van Wassanhove, L.N. (2004) Closed-Loop Supply Chain Models with Product Remanufacturing. Management Science, 50, 239-252. http://dx.doi.org/10.1287/mnsc.1030.0186

[69] Srivastava, S.K. and Srivastava, R.K. (2006) Managing Product Returns for Reverse Logistics. International Journal of Physical Distribution \& Logistics Management, 36, 524-546. http://dx.doi.org/10.1108/09600030610684962

[70] Roy, J., Nollet, J. and Beaulieu, M. (2006) Reverse Logistics Networks and Governance Structures. Supply Chain Forum: An International Journal, 7, 58-67. 